\title{
А. К. ЧЕРЕДНИЧЕНКО
}

\section{Национальный университет кораблестроения имени адмирала Макарова, Украина \\ ОСОБЕННОСТИ ПРИМЕНЕНИЯ ПРОДУКТОВ КОНВЕРСИИ МЕТАНОЛА В СУДОВОЙ ГАЗОТУРБИННОЙ УСТАНОВКЕ С ТЕРМОХИМИЧЕСКОЙ РЕГЕНЕРАЦИЕЙ СБРОСНОГО ТЕПЛА}

\begin{abstract}
Предметом исследования в статье являются проиессы преобразования энергии топлива в судовой газотурбинной установке с термохимической регенерацией. Рассмотрены современные подходы к оценке энергоэффективности судовых энергетических установок. Проанализированы характеристики традиционных и альтернативных судовых топлив. Обсуждаются аспекты применения метанола, как судового топлива с низким содержанием углерода. Предложено повысить эффективность применения метанола путем использования синтез-газа, полученного за счет термохимической регенерации тепла вторичных энергоресурсов судовых двигателей. Основной целью исследования является анализ влияния на энергоэффективность паровой термохимической конверсии метанола ограничений, связанных с системой подачи газообразного топлива в двигатель. Проведен анализ влияния давления в термохимическом реакторе на эффективность паровой конверсии метанола. Представлены расчетные схемы двух вариантов судовой газотурбинной установки с термохимической регенерацией тепла путем паровой конверсии метанола. Эффективность конверсии метанола определялась потенциалом теплоты отходящих газов и рассчитывалась с учетом теплового баланса термохимического реактора. Модель реактора выполнена двухкомпонентной. Математическая модель турбокомпрессорного блока базируется на укрупненном расчете с учетом потерь полного давления во всех элементах газовоздушного тракта. Представлены результаты математического моделирования процессов в установках на базе газотурбинных двигателей простого и регенеративного ичикла в условиях фиксированного расход метанола, фиксированной температуры газа перед турбиной для параметров окружающей среды по ISO 19859:2016. Выявлена эффективность схемы с проведением паровой конверсии метанола при давлениях соответствующих рабочему давлению в камере сгорания. Повышение энергоэффективности установки составляет $3 . .5 \%$ при базовых параметрах и $10 \ldots 11 \%$ для более высоких температур конверсии или для каталитических реакторов. Результаты исследований могут быть использованы при проектировании перспективных энергетических установок.
\end{abstract}

Ключевые слова: энергетическая установка; конверсия метанола; термохимическая регенерация тепла; газотурбинный двигатель; синтез-газ.

\section{Введение}

Рост объемов мировой торговли продуцирует дальнейший спрос на транспортировку грузов водным путем. Развитие новых технологий рационального использования энергии топлива, ужесточение требований по снижению влияния судовой энергетики на окружающую среду потребовало трансформирования подходов к формированию критериев оценки энергоэффективности судовых энергетических установок. Международная морская организация в соответствии с современными подходами выработала критерий, учитывающий как эффективность использования энергии топлива, так и воздействие энергоустановки на окружающую среду EEDI (Energy Efficiency Design Index) (рис. 1).

Критерий энергоэффективности судна представляет собой отношение массы произведенного энергетической установкой судна парникового газа (GHG) к величине транспортной работы судна [1].

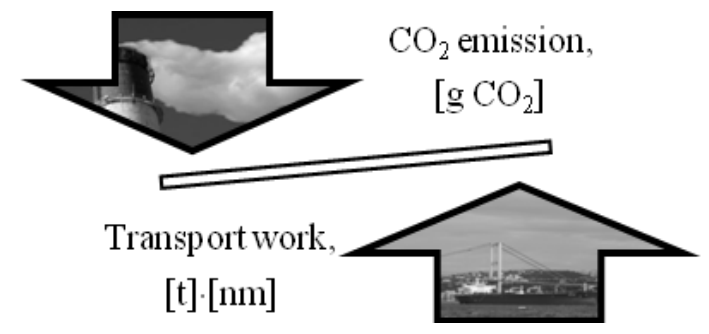

Рис. 1 Физический смысл индекса энергоэффективности

Внедрение энергосберегающих технологий проводится поэтапно, с ужесточением требований к концу третьего этапа (с 01.01.2025 г.) на $30 \%$. 
Это требует как адаптации в судовую энергетику существующих энергосберегающих технологий [2-4], так и разработки новых перспективных схемных решений [5].

\section{Анализ последних исследований и публикаций}

Одним из путей уменьшения выбросов парниковых газов является применение топлив с низким содержанием углерода, в том числе, так называемых, альтернативных. Следует отметить, что грань между традиционным и альтернативным вариантом всегда условна и часто актуальна на весьма короткий промежуток времени, после которого альтернативное может стать традиционным. Так в прогнозе авторитетного классификационного общества Lloyd's Register [6] предложено рассматривать в качестве традиционных судовых топлив две категории нефтяных топлив: легкие MDO/MGO - и тяжелые с разным содержанием серы - HFO/LSHFO. Остальные топлива (табл. 1), включая получивший весьма широкое распространение сжиженный при- родный газ (LNG) предложено рассматривать в качестве альтернативных.

Анализ перспективных топлив позволяет отметить, что метанол/биометанол является топливом с низким содержанием углерода, удобен для хранения в жидкой фазе. В тоже время метанол имеет малую низшую располагаемую теплотворную способность, что сдерживает эффективность его применения. Утилизация сбросного тепла двигателей и элементов энергетических установок позволяет повысить эффективность использования энергии топлива. Одним из перспективных методов повышения энергоэффективности есть термохимическая конверсия углеводородных топлив за счет утилизации вторичных энергоресурсов двигателей внутреннего сгорания [7-9], газотурбинных двигателей $[10,11]$ и теплотехнического оборудования [12].

Ранее проведенные исследования показывают, что располагаемого температурного диапазона отходящих газов современных серийных газотурбинных двигателей (ГТД) достаточно для эффективной паровой конверсии метанола при термохимической регенерации тепла $[13,14]$.

Таблица 1

Характеристики традиционных и альтернативных судовых топлив $[1,6]$

\begin{tabular}{|c|c|c|c|}
\hline $\begin{array}{c}\text { Название } \\
\text { (обозначение) }\end{array}$ & Тип топлива & Исходное сырье & Комментарий \\
\hline $\mathrm{MDO} / \mathrm{MGO}$ & Легкое, дистиллятное & Нефть & $\begin{array}{l}\text { Композиция легких фракций с } \\
\text { остаточными, низкое содержание серы }\end{array}$ \\
\hline Bio MDO & $\begin{array}{l}\text { Легкое, биодизель } \\
\text { (1,2 поколение) }\end{array}$ & $\begin{array}{l}\text { Рапсовое масло, } \\
\text { Лигноцеллюлоза }\end{array}$ & $\begin{array}{l}\text { Возможна смесь с МDO для снижения } \\
\text { GHG }\end{array}$ \\
\hline $\mathrm{HFO}$ & Тяжелое, остаточное & Нефть & $\begin{array}{l}\text { Основное судовое топливо с конку- } \\
\text { рентной ценой, но с наибольшим вы- } \\
\text { бросом GHG }\end{array}$ \\
\hline Bio HFO & Безприсадочное топливо & Рапсовое масло & $\begin{array}{l}\text { Возможно для замены HFO с целью } \\
\text { снижения выбросов GHG }\end{array}$ \\
\hline LSHFO & $\begin{array}{l}\text { Остаточное топливо с } \\
\text { низким содержанием серы }\end{array}$ & Нефть & $\begin{array}{llll}\text { Конкурентно по цене, } & \text { но } & \text { с } \\
\text { содержанием серы не более } & 0,5 \% & \text { с } \\
\text { целью снижения GHG } & & & \end{array}$ \\
\hline Bio LSHFO & Как Вio HFO & Как Вio HFO & Как Вio HFO \\
\hline LNG & $\begin{array}{l}\text { Сжиженный природный } \\
\text { газ }\end{array}$ & Природный газ & $\begin{array}{l}\text { Конкурентно по цене, обеспечивает } \\
\text { низкие выбросы GHG, активно внедря- } \\
\text { ется }\end{array}$ \\
\hline Bio LNG & Сжиженный биогаз & Лигноцеллюлоза & $\begin{array}{l}\text { Как LNG, но с большим сроком окупа- } \\
\text { емости снижения выбросов GHG }\end{array}$ \\
\hline LPG & Сжиженный нефтяной газ & Пропан, бутан & Обеспечивает низкие выбросы GHG \\
\hline $\mathrm{H} 2$ & Водород & Метан & Не дает выбросов углерода \\
\hline Bio H2 & LNG & Лигноцеллюлоза & Как Н2 \\
\hline $\mathrm{EtOH}$ & Этанол & Этилен & $\begin{array}{l}\text { Имеет низкие показатели содержания } \\
\text { углерода }\end{array}$ \\
\hline Bio EtOH & Биоэтанол & $\begin{array}{l}\text { Продукты броже- } \\
\text { ния }\end{array}$ & Как ЕtOH \\
\hline $\mathrm{MeOH}$ & Метанол & Метан & $\begin{array}{l}\text { Имеет наиболее низкие показатели } \\
\text { содержания углерода, подходит для } \\
\text { двухтопливных двигателей }\end{array}$ \\
\hline Bio MEOH & Метанол & Лигноцеллюлоза & Как МЕOH \\
\hline
\end{tabular}


Полученный в результате конверсии метанола синтез-газ обладает значительно более низкой теплотворной способностью, чем природный газ, который является традиционным топливом для серийных ГТД. Применение продуктов конверсии метанола, как альтернативного топлива в судовой газотурбинной установке с термохимической регенерацией (ГТД+ТХР) невозможно без учета влияния на ее энергоэффективность ограничений, связанных с системой подачи газообразного топлива в двигатель.

Необходимость реализации мероприятий по выполнению требований законодательных актов IMO по снижению влияния судовой энергетической установки на окружающую среду определяет запрос практики, направленный на применение топлив с низким содержанием углерода, в том числе метанола. Целью представленной работы является оценка методами математического моделирования, влияния выбора параметров системы подачи топливного газа на эффективность установки при работе на продуктах паровой конверсии метанола.

\section{Изложение основного материала}

При паровой конверсии углеводородных топлив, в том числе и метанола основными являются эндотермические реакции парового риформинга и декомпозиции, а также экзотермическая реакция сдвига водяного газа [15]:

$$
\begin{aligned}
& \mathrm{C}_{\mathrm{n}} \mathrm{H}_{\mathrm{m}} \mathrm{O}_{1}+\mathrm{H}_{2} \mathrm{O} \rightarrow \mathrm{H}_{2}+\mathrm{CO}, \Delta \mathrm{H}>0, \\
& \mathrm{C}_{\mathrm{n}} \mathrm{H}_{\mathrm{m}} \mathrm{O}_{1} \rightarrow \mathrm{CH}_{4}+\mathrm{H}_{2}+\mathrm{CO}, \Delta \mathrm{H}>0, \\
& \mathrm{CO}+\mathrm{H}_{2} \mathrm{O} \leftrightarrow \mathrm{H}_{2}+\mathrm{CO}_{2}, \Delta \mathrm{H}<0 .
\end{aligned}
$$

Таким образом, основными компонентами синтез-газа, которые получены в результате паровой конверсии будут $\mathrm{H}_{2}, \mathrm{CO}, \mathrm{CO}_{2}, \mathrm{CH}_{4}, \mathrm{H}_{2} \mathrm{O}$. Результаты моделирования процессов паровой конверсии метанола в реакторе на основе метода минимизации свободной энергии Гиббса представлены достаточно широко $[11,16]$. Установлено влияние температуры на процесс паровой конверсии и выявлен диапазон температур эффективной конверсии. Так в диапазоне температур $600 \ldots 750 \mathrm{~K}$, соответствующих температуре отходящих газов серийных отечественных ГТД происходит эффективная конверсия метанола. Исследование влияния давления на процесс конверсии, которые были проведены автором методами математического моделирования, совпадают с результатами других публикаций. Установлено, что рост давления приводит к росту температуры, которая необходима для эффективной конверсии. В тоже время, для эффективной организации рабочих процессов в камере сгорания газотурбинного двигателя, давление подачи топлива в форсунку должно превышать давление воздуха за компрессором. Это определило необходимость исследования влияния энергетических затрат на сжатие синтез-газа перед подачей в камеру сгорания и сравнение эффективности конверсии при разных уровнях давлений в реакторе - риформере. Принципиально возможна реализация двух конструктивных схем:

1. Проведение в термохимическом реакторериформере паровой конверсии метанола при давлениях близких к атмосферному с последующей дегидрацией полученного синтез-газа. Для организации процесса горения в камере сгорания ГТД, осушенный синтез-газ должен быть сжат компрессором до номинального давления подачи топлива в форсунку (выше давления за компрессором). Преимущества - смещение диапазона эффективной конверсии в область относительно низких температур. Осушенный синтез-газ имеет значительно меньшее содержание негорючих компонентов, что существенно упрощает процессы смесеобразования и сжигания в камере сгорания. Недостатки - потеря теплового потенциала парогазовой смеси при дегидрации синтез-газа, значительные энергозатраты на привод компрессора подачи газа. На рис. 2, а показана схема такой установки на базе ГТД простого цикла.

2. Проведение конверсии при давлениях, соответствующих давлению подачи топлива в форсунку. Преимущества - использование теплового потенциала парогазовой смеси, которая после реактора имеет достаточно высокую температуру и подается в камеру сгорания как в цикле STIG. Недостатки смещение диапазона эффективной конверсии в область относительно высоких температур. На рис. 2, б показана схема установки второго типа на базе газотурбинного двигателя регенеративного цикла.

С целью исследования влияния выбора схемы установки ГТД+ТХР на ее эффективность было проведено математическое моделирование процессов в установках на базе ГТД простого и регенеративного цикла.

В качестве базовых параметров приняты характеристики ГТД UGT2500 и UGT3200RG производства «Зоря»-«Машпроект», предназначенные для привода генератора. Основные характеристики базовых двигателей при работе на природном газе приведены в табл. 2 [17].

Математическая модель турбокомпрессорного блока базируется на укрупненном расчете ГТД [18] с учетом потерь полного давления во всех элементах газовоздушного тракта и отбора воздуха на охлаждение лопаток турбины. Модель камеры сгорания предусматривает комбинированное химическое и 
фазовое равновесие. Предусматривается минимизация свободной энергии Гиббса для определения продуктов реакции. Эффективность конверсии метанола определяется потенциалом теплоты отходящих газов и рассчитывается с учетом теплового баланса термохимического реактора. Модель реактора выполнена двухкомпонентной.

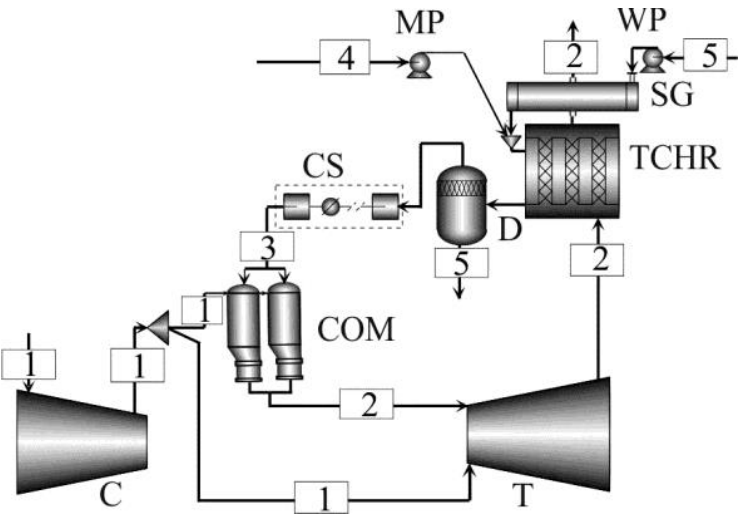

a)

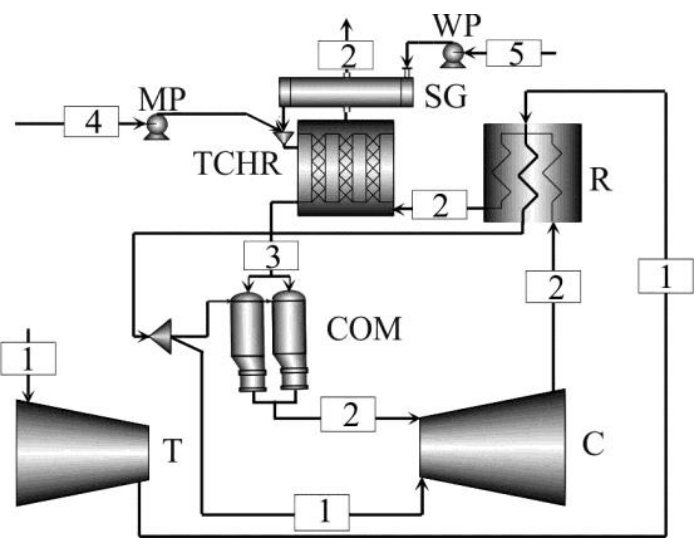

б)

Рис. 2. Схема различных вариантов установки ГТД+ТХР с паровой конверсией метанола: a - на базе ГТД простого цикла;

б - на базе регенеративного ГТД, где:

C - компрессор; Т - турбина; COM - камера сгорания; TCHR - реактор; R - регенератор; SG - парогенератор; WP - насос подачи воды; MP - насос подачи метанола; D - дегидратор; CS - компрессор синтез-газа; 1 - воздух; 2 - газы; 3 - синтез-газ; 4 - метанол; 5 - вода

Таблица 2

Основные характеристики базовых двигателей UGT 2500 и UGT 3200RG

\begin{tabular}{|c|c|c|}
\hline Параметр & UGT 2500 & UGT 3200RG \\
\hline Мощность, МВт & 2,85 & 3,40 \\
\hline Расход воздуха, кг/с & 14,9 & 16 \\
\hline $\begin{array}{c}\text { Степень повышения } \\
\text { давления }\end{array}$ & 12 & 7 \\
\hline Степень регенерации & - & 0,85 \\
\hline $\begin{array}{c}\text { Температура газа } \\
\text { перед турбиной, К }\end{array}$ & \multicolumn{2}{|c|}{1224} \\
\hline
\end{tabular}

Моделирование проводилось для указанных в табл. 2 параметрах базовых турбокомпрессорных блоков при следующих ограничениях: фиксированный расход метанола, как топлива; фиксированная температура газа перед турбиной; параметры окружающей среды соответствуют ISO 19859:2016.

В качестве критерия эффективности принято отношение мощности установки ГТД+ТХР к мощности базового двигателя, определенное как

$$
\mathrm{C}_{\mathrm{ef}}=\left(\mathrm{Ne}-\sum \mathrm{N}_{\mathrm{add}}\right) / \mathrm{Ne}_{\text {base }},
$$

где $\mathrm{Ne}$ - механическая мощность на выходном валу газотурбинного двигателя установки ГТД+ТХР, кВт; $\sum \mathrm{N}_{\text {add }}$ - суммарные затраты мощности на привод насосов подачи воды, метанола и компрессор синтез-газа, кВт; $\mathrm{Ne}_{\text {base }}$ - механическая мощность на выходном валу базового газотурбинного двигателя при фиксированной подаче метанола, соответствующей 100 \% нагрузке, кВт.

Математическое моделирование процессов позволило сравнить энергетические затраты на сжатие осушенного синтез-газа (схема на рис. 2, а) и влияние давления в реакторе $\mathrm{p}_{\mathrm{r}}$ на эффективность конверсии метанола (схема на рис. 2, б). На рис. 3 показано изменение выходной мощности установки (за вычетом затрат энергии на привод насосов и компрессоров) для разных схем проведения конверсии и подачи топливного газа.

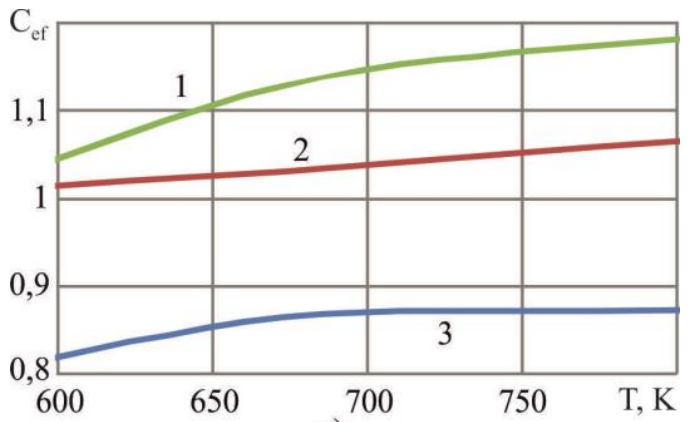

a)

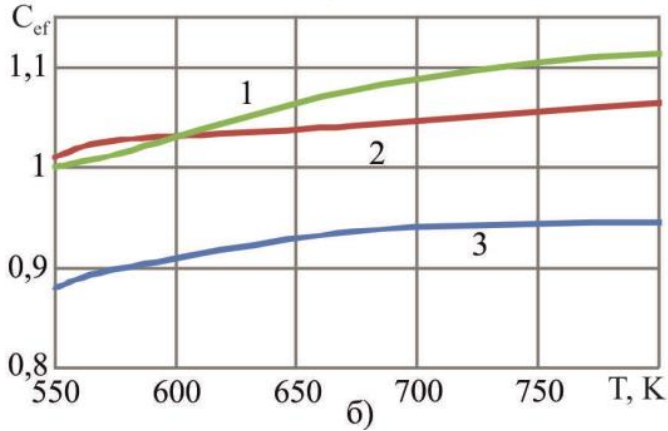

Рис. 3. Изменение полезной мощности установки ГТД+ТХР на базе: а - ГТД простого цикла UGT 2500; б - ГТД регенеративного цикла UGT 3200RG, где: $1-\mathrm{p}_{\mathrm{r}}=0,2 \mathrm{MПа}$, без учета затрат энергии на привод компрессора синтез-газа; $2-\mathrm{p}_{\mathrm{r}}=2 \mathrm{MПа} \mathrm{для} \mathrm{UGT} \mathrm{2500,} \mathrm{p}_{\mathrm{r}}=1 \mathrm{MПа}$ для UGT3200RG; $3-\mathrm{p}_{\mathrm{r}}=0,2 \mathrm{MПа}$ 
Выявлено, что схема на рис. 2, а неэффективна, так как затраты энергии на сжатие осушенного синтез-газа превышают повышение энергоэффективности за счет паровой конверсии метанола. В результате эффективность схемы на рис. 2, а ниже, чем в базовом ГТД без регенерации. В схеме на рис. 2, б парогазовая смесь после реактора, имеющая достаточно высокую температуру подается в камеру сгорания как в цикле STIG. Применение такой схемы позволяет повысить энергоэффективность установки с базовыми параметрами на $3 . .5 \%$, а для более высоких температур конверсии или для каталитических реакторов до $10 \ldots 11 \%$.

Полученный в результате конверсии метанола синтез-газ имеет высокое содержание водорода и негорючих (балластных) компонентов, что вызывает проблемы с организацией эффективного рабочего процесса в камере сгорания ГТД. Согласно результатам математического моделирования, продукты конверсии содержат более $50 \%$ водорода, 30-40\% водяного пара и $10-20 \% \mathrm{CO}_{2}$.

\section{Заключение}

1. Проведенное исследование позволило оценить влияние энергетических затрат на сжатие синтез-газа перед подачей в камеру сгорания и сравнить эффективность конверсии при разных уровнях давлений в реакторе - риформере. Выявлено, что схема установки ГТД+ТХР, предусматривающая проведение паровой конверсии метанола при давлениях близких к атмосферному с дальнейшей дегидрацией и сжатием полученного синтез-газа неэффективна. Схема установки ГТД+ТХР с проведением паровой конверсии метанола при давлениях соответствующих рабочему давлению в камере сгорания дает повышение энергоэффективности установки на $3 \ldots 5 \%$ при базовых параметрах и $10 \ldots 11 \%$ для более высоких температур конверсии или для каталитических реакторов.

2. Представляет интерес дальнейшее исследование рабочих процессов в камере сгорания газотурбинного двигателя, входящего в состав установки ГТД+ТХР с целью внесения необходимых конструктивных изменений для обеспечения эффективной работы на продуктах паровой конверсии метанола.

\section{Литература}

1. IMO Train the Trainer (TTT) Course on Energy Efficient Ship Operation. Module 2 - Ship Energy Efficiency Regulations and Related Guidelines [Электронный ресурс]. - Режим доступа: http://www.imo. org/en/OurWork/Environment/PollutionPrevention/AirP
ollution/Documents/Air\%20pollution/M2\%20EE $\% 20$ regulations\%20and\%20guidelines\%20final.pdf. 01.05.2019.

2. Matveev, I. Investigation of a reverse-vortex plasma assisted combustion system [Text] / I. Matveev, S. Serbin // Proc. of the ASME. Heat Transfer Summer Conf., Puerto Rico, USA. - 2012. - P. 133-140.

3. Serbin, S. Features of liquid-fuel plasmachemical gasification for diesel engines [Text] / S. Serbin // IEEE Trans. Plasma Sci. - 2006. - Vol. 34, No. 6. - P. 2488-2496.

4. Serbin, S. I. Plasma Assisted Reforming of Natural Gas for GTL. Part I [Text] / S. I. Serbin, I. B. Matveev, M. A. Goncharova // IEEE Trans. Plasma Sci. - 2014. - Vol. 42, No 12. - P. 3896-3900.

5. Чередниченко, А. К. Влияние климатических факторов на эффективность утилизационной металлогидридной установки двухтопливного малооборотного ДВС [Текст] / A. К. Чередниченко, М. Р. Ткач // Вісник НТУ «ХПІ». - 2017. - № 10(1232). - C. 85-91. DOI: 10.20998/2078774X.2017.10.12.

6. Global Marine Fuel Trends 2030 [Электронный ресурс]. - Режим доступа: http://discovery. ucl.ac.uk/1472843/1/Global_Marine_Fuel_Trends_ 2030.pdf. - 01.05.2019.

7. Poran, A. Energy efficiency of a direct injection internal combustion engine with high-pressure methanol steam reforming [Text] / A. Poran, L. Tartakovsky // Energy. - 2015. - Vol. 88. - P. 506-514.

8. Tartakovsky, L. Modeling Methanol Steam Reforming for Internal Combustion Engine [Text] / L. Tartakovsky, V. Baibikov, M. Veinblat // Energy and Power. - 2014. - Vol. 4(1A). - P. 50-56. DOI: 10.5923/s.ep.201401.04

9. Tartakovsky, L. Comparative performance analysis of SI engine fed by ethanol and methanol reforming products [Text] / L. Tartakovsky, V. Baibikov, M. Veinblat // SAE Technical Paper. - 2013. - Paper 11. - P. 1-14. DOI: 10.4271/2013-01-2617.

10. Cherednichenko, O. Analysis of Efficiency of the Ship Propulsion System with Thermochemical Recuperation of Waste Heat [Text] / O. Cherednichenko, S. Serbin // Journal of Marine Science and Application. - 2018. - Vol. 17, Issue 1. - P. 122-130. DOI: https://doi.org/10.1007/s11804-018-0012-x.

11. Cherednichenko, O. Analysis of efficiency of diesel-gas turbine power plant with thermo-chemical heat recovery [Text] / O. Cherednichenko // MOTROL. Commission of motorization and energetics in agriculture Lublin-Rzeszow. - 2015. - Vol. 17, No. 2. - P. 25-28

12. Pashchenko, D. Thermodynamic equilibrium analysis of combined dry and steam reforming of propane for thermochemicalwaste-heat recuperation [Text] / D. Pashchenko // Int J Hydrogen Energy. - 2017. - Vol. 42(22). - P. 14926-14935.

13. Чередниченко, А. К. Повышение эффективности энергетических установок судов-газовозов применением термохимических технологий [Текст] 
/ А. К. Чередниченко // Двигатели внутреннего сгорания. - 2017. - № 1. - C. 46-51. DOI: 10.20998/ 0419-8719.2017.1.09

14. Чередниченко, А. К. Моделирование энергокомплексов с термохимической регенерацией тепла для судов газовозов [Текст] / A. К. Чередниченко // Вестник двигателестроения. - 2016. - Vol. 2. - C. 36-41.

15. Tartakovsky, L. Fuel reforming in internal combustion engines [Text] / L. Tartakovsky, M. Sheintuch // Progress in Energy and Combustion Science. - 2018. - Vol. 67. - P. 88-114.

16. Poran, A. Performance and emissions of a direct injection internal combustion engine devised for joint operation with a high- thermochemical recuperation system [Text] / A. Poran, L. Tartakovsky // International journal of hydrogen energy. - 2017. - Vol. 42. -P. 15652-15668.

17. Романовський, Г. Ф. Сучасні газотурбінні агрегати. Т. 1 : Агрегати виробництва Украӥни та Росії [Текст] / Г. Ф. Романовський, С. I. Сербін, В. М. Патлайчук. - Миколаїв : НУК, 2005. - 344 c.

18. Романовський, Г. Ф. Теоретичні основи проектування суднових газотурбінних агрегатів [Текст] / Г. Ф. Романовський, М. В. Вашиленко, С. І. Сербин. - Миколаїв : УДМТУ, 2003. - 304 с.

\section{References}

1. IMO Train the Trainer (TTT) Course on Energy Efficient Ship Operation. Module 2 - Ship Energy Efficiency Regulations and Related Guidelines. - 2016. Available at: http://www.imo.org/en/OurWork/ Environment/PollutionPrevention/AirPollution/Pages/IMOTrain-the-Trainer-Course.aspx (accessed 1.05.2019).

2. Matveev, I., Serbin, S. Investigation of a reverse-vortex plasma assisted combustion system. Proc. of the ASME. Heat Transfer Summer Conf., Puerto Rico, USA, 2012, HT2012-58037, pp. 133-140.

3. Serbin, S. Features of liquid-fuel plasmachemical gasification for diesel engines. IEEE Trans. Plasma Sci., 2006, vol. 34, no. 6, pp. 2488-2496.

4. Serbin, S. I., Matveev, I. B., Goncharova, M. A. Plasma Assisted Reforming of Natural Gas for GTL. Part I. IEEE Trans. Plasma Sci., 2014, vol. 42, no. 12 , pp. 3896-3900.

5. Cherednichenko, O., Tkach, M. Vliynie klimaticheskikh faktorov na efektivnost utilizatsionnoy metallogidridnoy ustanovki dvukhtoplivnogo malooborotnogo DVS gazovoza [Influence of Climatic Factors on the Efficiency of Disposal Metal-Hydride Unit for the Double-Fuel Low-Speed Internal Combustion Engine of Gas Tankers]. Trudy NTU “KhPI" - Bulletin of NTU "KhPI", 2017, Vol. 10(1232), pp. 85-91. DOI: 10.20998/2078-774X.2017.10.12.

6. Global Marine Fuel Trends 2030. Available at: http://discovery.ucl.ac.uk/1472843/1/Global_Marine_Fu el_Trends_2030.pdf (accessed 1.05.2019).
7. Poran, A., Tartakovsky, L. Energy efficiency of a direct injection internal combustion engine with highpressure methanol steam reforming. Energy, 2015, Vol. 88, pp. 506-514.

8. Tartakovsky, L., Baibikov, V., Veinblat, M., Modeling Methanol Steam Reforming for Internal Combustion Engine. Energy and Power, 2014, Vol. 4(1A), pp. 50-56. DOI: 10.5923/s.ep.201401.04

9. Tartakovsky, L., Baibikov, V., Veinblat, M., Comparative performance analysis of SI engine fed by ethanol and methanol reforming products. SAE Technical Paper, 2013, Paper 11, pp. 1-14. DOI: 10.4271/2013-01-2617.

10. Cherednichenko, O., Serbin, S. Analysis of Efficiency of the Ship Propulsion System with Thermochemical Recuperation of Waste Heat. Journal of Marine Science and Application, 2018, vol. 17, iss. 1, pp. 122-130. DOI: 10.1007/s11804-018-0012-x.

11. Cherednichenko, O. Analysis of efficiency of diesel-gas turbine power plant with thermo-chemical heat recovery. MOTROL. Commission of motorization and energetics in agriculture. Lublin-Rzeszow, 2015, vol. 17 , no. 2 , pp. 25-28.

12. Pashchenko, D. Thermodynamic equilibrium analysis of combined dry and steam reforming of propane for thermochemicalwaste-heat recuperation. Int. J. Hydrogen Energy, 2017, vol. 42(22), pp. 14926-14935.

13. Cherednichenko, O. Povyshenie jeffektivnosti jenergeticheskih ustanovok sudov-gazovozov primeneniem termohimicheskih tehnologij [Increase of efficiency of ship power plants of gas carriers with application of thermochemical technologies]. Dvigateli vnutrennego sgoranija - ICE, 2017, no. 1, pp. 46-51. DOI: 10.20998/0419-8719.2017.1.09

14. Cherednichenko, A. K. Modelirovanie energokompleksov s termokhimicheskoi regeneratsiei tepla dlya sudov-gazovozov [Modeling of efficiency of ship power plants with ther-mochemical heat recovery for liquefied natural gas carriers]. Vestnik dvigatelestroenija - Herald of Aeroenginebuilding, 2016, vol. 2, pp. 36-41.

15. Tartakovsky, L., Sheintuch, M. Fuel reforming in internal combustion engines. Progress in Energy and Combustion Science, 2018, vol. 67, pp. 88-114.

16. Poran, A., Tartakovsky, L. Performance and emissions of a direct injection internal combustion engine devised for joint operation with a high- thermochemical recuperation system. International journal of hydrogen energy, 2017, vol. 42, pp. 15652-15668.

17. Romanovsky, G. F., Serbin, S. I., Patlaychuk, V. M. Suchasni gazoturbinnye agregatu [Advanced gas turbine plants], 2005, Nikolaev, NUK Publ. 344 p.

18. Romanovsky, G. F., Serbin, S. I., Vaschilenko, M. V. Teorety 'chni osnovy` proektuvannya sudnovy`x gazoturbinny`x agregativ [Theoretical bases of design of ship gas turbine units], 2003, Nikolaev, UDMTU Publ. 304 p. 


\section{ОСОБЛИВОСТІ ЗАСТОСУВАННЯ ПРОДУКТІВ КОНВЕРСІЇ МЕТАНОЛУ У СУДОВОЇ ГАЗОТУРБІННОЇ УСТАНОВКИ З ТЕРМОХІМІЧНОЮ РЕГЕНЕРАЦЕЮ СКІДНОГО ТЕПЛА}

\section{О. К. Чередниченко}

Предметом дослідження в статті є процеси перетворення енергії палива в судновий газотурбінної установки 3 термохімічною регенерацісю. Розглянуто сучасні підходи до оцінки енергоефективності суднових енергетичних установок. Проаналізовано характеристики традиційних та альтернативних суднових палив. Обговорюються аспекти застосування метанолу, як суднового палива 3 низьким вмістом вуглецю. Запропоновано підвищити ефективність застосування метанолу шляхом використання синтез-газу, отриманого за рахунок термохімічної регенерації тепла вторинних енергоресурсів суднових двигунів. Основною метою дослідження $є$ аналіз впливу на енергоефективність парової термохімічної конверсії метанолу обмежень, які пов'язані з системою подачі газоподібного палива в двигун. Проведено аналіз впливу тиску в термохімічному реакторі на ефективність парової конверсії метанолу. Представлені розрахункові схеми двох варіантів суднової газотурбінної установки з термохімічною регенерацією тепла шляхом парової конверсії метанолу. Ефективність конверсії метанолу визначалася потенціалом теплоти відхідних газів і розраховувалася з урахуванням теплового балансу термохімічного реактора. Модель реактора виконана двохкомпонентною. Математична модель турбокомпресорного блоку базується на укрупненому розрахунку з урахуванням втрат повного тиску у всіх елементах газоповітряного тракту. Представлені результати математичного моделювання процесів в установках на базі газотурбінних двигунів простого та регенеративного циклу в умовах фіксованої витрати метанолу, фіксованої температури газу перед турбіною та при параметрів навколишнього середовища згідно з ISO 198591:2016. Виявлено ефективність схеми з проведенням парової конверсії метанолу при тиску, який відповідає робочому тиску в камері згоряння. Підвищення енергоефективності установки становить $3 \ldots 5$ \% при базових параметрах та $10 \ldots 11 \%$ для більш високих температур конверсії або для каталітичних реакторів.

Ключові слова: енергетична установка; конверсія метанолу; термохімічна регенерація тепла; газотурбінний двигун; синтез-газ

\section{PECULIARITIES OF APPLICATION OF METHANOL CONVERSION PRODUCTS IN A SHIP GAS TURBINE PLANTS WITH THERMOCHEMICAL REGENERATION OF WASTE HEAT}

\section{O. K. Cherednichenko}

The research's subject is the processes of energy transformation of fuel in the ship gas turbine plant with thermochemical regeneration. Modern approaches to assessing the energy efficiency of ship power plants were considered. The characteristics of traditional and alternative marine fuels were analyzed. The use of methanol as a lowcarbon marine fuel is discussed. It is proposed to increase the efficiency of methanol use by using synthesis gas obtained through thermochemical heat recovery of secondary energy resources of ship engines. The main objective of the study is to analyze the effects on the energy efficiency of steam thermochemical transformation of methanol of the limitations associated with the system of supplying gaseous fuel to the engine. The influence of pressure in the thermochemical reactor on the steam's efficiency of reforming of methanol was analyzed. The design schemes of two variants of the ship gas turbine installation with thermochemical heat recovery by steam conversion of methanol are presented. The methanol conversion efficiency was determined by the heat potential of the exhaust gases and was calculated based on the thermal balance of the thermochemical reactor. The reactor's model is two- component. The mathematical model of the turbocompressor unit is based on an enlarged calculation taking into account the total pressure loss in all elements of the gas-air duct. The results of mathematical modeling of processes in plants based on gas turbine engines of simple and regenerative cycles under conditions of fixed methanol's consumption, the fixed temperature of the gas in the turbine's front for environmental parameters according to ISO 19859: 2016 are presented. The efficiency of the scheme which used steam conversion of methanol at pressures corresponding to the working pressure in the combustion chamber was revealed. The increase in the energy efficiency of the installation is $3 \ldots 5 \%$ with basic parameters and $10 \ldots 11 \%$ for higher conduction temperatures or for catalytic reactors. The research results can be used in the promising power plants designing.

Keywords: ship power plant; methanol conversion; thermochemical recuperation; gas turbine engine; syngas.

Чередниченко Александр Константинович - канд. техн. наук, доцент кафедры судовых и стационарных энергетических установок Национального университета кораблестроения им. адмирала Макарова, Николаев, Украина.

Cherednichenko Oleksandr Constantinovich - Candidate of Technical Science, Assistant Professor of Dept. of ship and stationary power plants, Admiral Makarov National University of Shipbuilding, Ukraine, e-mail: oleksandr.cherednichenko@nuos.edu.ua, ORCID Author ID: 0000-0001-8746-9132, ResearcherID: K-3554-2018, https://scholar.google.com.ua/citations?user=XNrAwwUAAAAJ\&hl=en 